\title{
FEIÇÕES DE INTERAÇÃO VULCANO-SEDIMENTARES: EXEMPLOS NA BACIA DO PARANÁ (RS)
}

\author{
VOLCANO - SEDIMENTARY INTERACTION: EXAMPLES IN THE PARANÁ BASIN (RIO \\ GRANDE DO SUL STATE)
}

\author{
Fernando Rodrigues RIOS ${ }^{1}$, Ana Maria Pimentel MIZUSAKI ${ }^{1}$, Cassiana Roberta Lizzoni \\ MICHELIN ${ }^{2}$ \\ ${ }^{1}$ UFRGS, Instituto de Geociências, Programa de Pós-Graduação em Geociências, Campus do Vale - Porto Alegre (RS). \\ Email: fernandor.rios@hotmail.com, ana.mizusaki@ufrgs.br \\ ${ }^{2}$ UFRGS, Instituto de Geociências, Departamento de Mineralogia e Petrologia, Campus do Vale - Porto Alegre (RS). \\ Email: cassiana.michelin@ufrgs.br
}

Introdução
Interação vulcano-sedimentar
Contexto Regional
Localização
Materiais, Métodos e Técnicas
Resultados
Discussões
Conclusões
Agradecimentos
Referências Bibliográficas

RESUMO - A Sequência Juro-Cretácea da Bacia do Paraná composta por arenitos eólicos da Formação Botucatu sobrepostos por derrames vulcânicos da Formação Serra |Geral, possui feições de interação vulcano-sedimentares na interface entre essas duas unidades. O intenso magmatismo de caráter básico e, secundariamente ácido, recobriu um imenso campo de dunas eólicas e permitiu a origem de diversas estruturas vulcano-sedimentares. Em afloramentos da borda atual da Bacia do Paraná, no estado do Rio Grande do Sul, observa-se uma variedade de feições de interação entre sedimentos consolidados ou inconsolidados, saturados ou não em água, com derrames de composição basáltica ou dacítica. As feições vulcano-sedimentares, encontradas na base e topo dos derrames, ocorrem de diferentes formas devido a temperatura das rochas vulcânicas e tipo de sedimento. Estas feições podem ser categorizadas de acordo com seu processo de formação em duas maneiras distintas: interação com o derrame ainda fluido, com temperatura elevada e parcialmente cristalizado, onde a presença de água ou umidade sobre os sedimentos facilita a interação; e interação a partir de processos posteriores tais como, erosão e intemperismo com o derrame já consolidado. As feições vulcano-sedimentares compreendem: estrias de fluxo, brechas, diques de arenito, fraturas com arenitos e geodos.

Palavras-chave: Interação, Feições vulcano-sedimentares, Bacia do Paraná.

\begin{abstract}
The Jurassic-Cretaceous Sequence of the Paraná Basin including eolic sandstones of the Botucatu Formation are superimposed by volcanic eruption from Serra Geral Formation, this sequence has features of volcano-sedimentary interaction between the interface of these two units. Intense basic magmatism and secondarily acidic magmatism covered a huge field of dunes, this magmatism led to origin of several volcano-sedimentary structures. Outcrops of Paraná Basin margin, Rio Grande do Sul state show a variety of interaction characteristics between consolidated or unconsolidated sediments, they can be saturated or not of water, basaltic or dacitic composed. Volcano-sedimentary features, found on the base and top of the flow, occur in different forms due to the temperature of the volcanic rocks and the type of sediment. These features can be categorized according to their production process divided in two: interaction with the hot fluid flow and partially crystallized, where the presence of water or moisture on the sediments make the interaction easier; interaction from later processes like erosion and weathering on consolidated flow. Volcano-sedimentary features include: flow streaks, breccias, sandstone dikes, sandstone fractures and geodes.
\end{abstract}

Keywords: Interaction, Volcano-sedimentary features, Paraná Basin.

\section{INTRODUÇÃO}

Rochas vulcânicas e rochas sedimentares têm sido objetos de estudos de forma isolada (Scherer, 1998, 2000; Nardy et al., 2008; Machado et al., 2009), porém análises da interação entre estas duas rochas (vulcanosedimentares) são relativamente recentes (Jerram \& Stollhofen, 2002; Skilling et al., 2002; Squire \& McPhie, 2002; Zimanowski \& Büttner, 2002; Petry et al., 2007; Waichel et al., 2007; Hole et al., 2013; Michelin, 2014). No entanto, os produtos da interação entre vulcânicas e sedimentos são fundamentais para reconstruções paleoambientais em análise de bacias, além de serem marcadores estrati- gráficos importantes, já que sua presença fornece uma idade relativa (MacDonald, 1939, Branney \& Suthren, 1988; Allen, 1992; Boulter, 1993; McPhie, 1993). Também, em muitas situações, estão associadas com mineralizações de ágata (Heemann, 1997; Strieder \& Heemann, 2006; Michelin, 2007, 2014; Rosa et al., 2016). Reis (2013) aponta que estas feições são fundamentais para o entendimento dos processos que ocorrem em reservatórios vulcânicos, análogos de interesse na explotação de hidrocarbonetos.

A interação entre vulcânicas e sedimentos pode ocorrer de forma concomitante com o 
derrame, com temperaturas relativamente elevadas e lavas parcialmente cristalizadas, ou em derrames já cristalizados em temperatura ambiente, por meio do intemperismo, erosão e sedimentação.

Os produtos da interação vulcanosedimentar originam-se assim pelo recobrimento ou o contato da lava/derrame com sedimentos, consolidados ou inconsolidados, saturados ou não em água.

Propagam-se, deste modo, por diversas sucessões sedimentares caracterizadas pela contemporaneidade entre sedimentação e magmatismo, sendo representados em ambientes sedimentares marinhos, lacustres e desérticos.

O magmatismo Juro-Cretáceo, que deu origem a Formação Serra Geral (Bacia do Paraná), é reconhecido pela sua magnitude, e está representado em um espesso pacote de derrames básicos e ácidos, estes em menor volume, associados com corpos intrusivos. Durante o extravasamento, estes derrames recobriram dunas eólicas ainda ativas associadas à Formação Botucatu. No contato entre estas unidades são marcantes as feições de interação vulcanosedimentares, que neste caso, devido à grande extensão e volume desta manifestação magmática ocorrem com frequência, em diferentes pontos da Bacia. Nesse sentido, optou-se por realizar esta pesquisa em áreas onde já haviam sido reconhecidas estas estruturas na interface lavasedimento. Deste modo, o trabalho objetivou-se em reconhecer estas feições tanto em escala macroscópica quanto microscópica, buscando assim, características distintivas entre os processos de interação entre as rochas vulcânicas e os sedimentos siliciclásticos que ocorrem na Bacia do Paraná.

\section{INTERAÇÃO VULCANO-SEDIMENTAR}

Durante muitos anos, o estudo das feições de interação entre lava e sedimento foi focado apenas em ambientes marinhos e lacustres (Almeida, 1954; McPhie \& Hunns, 1995;Mountney et al., 1998; Jerram et al., 1999a, b; McPhie \& Orth, 1999; Mountney et al.,1999; Jerram et al., 2000; Mountney \& Howell, 2000; Jerram \& Stollhofen, 2002), entretanto, descobertas em ambientes desérticos vêm recebendo destaque nos últimos anos, principalmente na Bacia do Paraná (Scherer, 1998, 2002; Petry, 2006; Waichel et al., 2006; Michelin, 2007; Petry et al., 2007; Waichel et al., 2007; Arioli et al., 2008; Holz et al., 2008; Perinotto et al., 2008; Waichel et al., 2008; Machado et al., 2009; Hartmann et al., 2012 a, b; Luchetti et al., 2014; Michelin, 2014).

A distinção entre as feições que resultam da interação entre derrames ácidos e básicos é assunto relativamente recente na literatura, poucos estudos são encontrados sobre o tema (Nardy et al., 2008; Michelin 2014; Polo, 2014). Pelo contrário, na Bacia do Paraná, os estudos acerca dos derrames básicos são relativamente comuns (Petry, 2006; Waichel et al., 2006;
Michelin, 2007; Petry et al., 2007; Waichel et al., 2007, 2008). A interação vulcano-sedimentar gera uma variedade de feições características, tais como: peperitos (brechas vulcanoclásticas), brechas sedimentares, diques de arenito, intertraps e feições de superfície, como dunas recobertas marcadas por estruturas estriadas, geodos e fraturas preenchidas por sedimentos.

Aspectos tanto do ponto de vista ígneo quanto do sedimentar, regem os processos responsáveis pela formação de rochas por meio da interação vulcano-sedimentar. O ambiente de colocação do corpo ígneo (intrusivo ou subaéreo), tipo de lava, composição, temperatura, velocidade de fluxo e teor de voláteis, relacionam-se às características de natureza ígnea. Ao passo que a granulometria do sedimento (fina a grossa), tamanho do grão, grau de compactação, seleção, porosidade, permeabilidade, composição e grau saturação em água, referem-se às condições sedimentares (Lorenz, 1984; Busby-Spera \& White, 1987; Jerram \& Stollhofen, 2002; Skilling et al., 2002; Squire \& McPhie, 2002; Zimanowski \& Büttner, 2002; Petry et al., 2007; Waichel et al., 2007; Hole et al., 2013).

\section{CONTEXTO REGIONAL}

A Bacia do Paraná é uma bacia paleozoica da Plataforma Sul-Americana, em cujo depocentro, estima-se aproximadamente 7.000 $\mathrm{m}$ de rochas sedimentares e rochas vulcânicas com idades do Ordoviciano ao Cretáceo (Zalán et al., 1988, 1990) (Figura 1). Recobre 1,6 milhões de $\mathrm{km}^{2}$ da porção centro leste da América do Sul, e está distribuída pelo Brasil, Uruguai, Paraguai e Argentina (Petri \& Fúlfaro, 1983). 


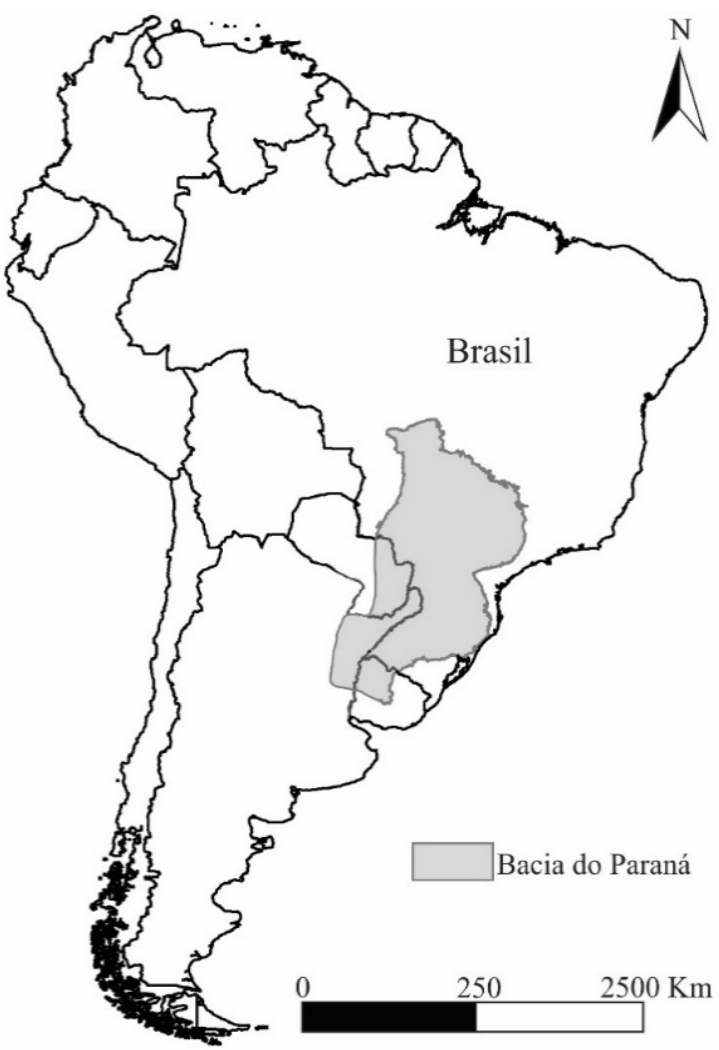

Figura 1 - Localização da Bacia do Paraná (modificado de Reis, 2013).

O registro vulcano-sedimentar da Bacia do Paraná é dividido em seis Supersequências, da base para o topo segundo Milani (1997): Rio Ivaí (Neo-Ordoviciano ao Eo-Siluriano), Paraná (Devoniano), Gondwana I (Neo-Carbonífero ao Eo-Triássico), Gondwana II (Meso-Triássico ao Neo-Triássico), Gondwana III (Neo-Jurássico ao Eo-Cretáceo) e Bauru (Eo-Cretáceo ao Neocretáceo).

A Supersequência Gondwana III é o intervalo estratigráfico de interesse neste trabalho e onde se encontram os arenitos predominantemente eólicos da Formação Botucatu e as rochas vulcânicas associadas à Formação Serra Geral (Figura 2)
A Formação Botucatu é considerada como um imenso campo de dunas eólicas com estratos cruzados de grande porte (até $30 \mathrm{~m}$ ). São arenitos quartzosos de coloração rosada, granulometria fina a média e grãos arredondados de aspecto fosco, caracterizando o transporte eólico. Em termos de espessura residual, provavelmente devido à preservação do paleo-relevo de dunas, pode atingir até $100 \mathrm{~m}$ de espessura conforme Scherer (1998, 2000, 2002).

A Formação Serra Geral compreende uma sucessão de derrames magmáticos e corpos intrusivos associados, com uma espessura residual máxima de cerca de $1.700 \mathrm{~m}$, na qual a predominância de basaltos de afinidade toleítica (90\%), seguido por andesitos toleíticos (7\%) e em menores proporções riolitos-riodacitos (3\%) especialmente nas porções mais superiores (Melfi et al., 1988; Piccirillo \& Melfi, 1988). Para Nardy et al. (2008), rochas vulcânicas ácidas (riolitos e riodacitos) representam cerca de 2,5\% do volume total da Formação Serra Geral e recobrem uma área de aproximadamente $64.000 \mathrm{~km}^{2}$

O início do magmatismo da Formação Serra Geral indica uma idade relativa para o término da sedimentação da Formação Botucatu conforme pode observado na figura 2. No entanto, são observados eventuais intertraps arenosos nas porções mais basais da Formação Serra Geral, ocasionando feições típicas de interação lava-sedimento ao longo deste contato. Este fato sugere que condições desérticas ultrapassaram este limite e persistiram por algum tempo durante as primeiras fases do evento vulcânico (Milani et al., 1998; Scherer, 2002).

\section{LOCALIZAÇÃO}

Visando caracterizar feições de interação vulcano-sedimentares, foram analisadas áreas preferencialmente ao longo da borda atual da Bacia do Paraná, no estado do Rio Grande do Sul. Nesta situação observam-se inúmeros afloramentos com a presença de rochas vulcânicas (sejam básicas e/ou ácidas), sedimentares (siliciclásticas) e as feições resultantes desta interação.

Foram escolhidas regiões onde afloram as feições resultantes da interação das formações
Botucatu e Serra Geral. Os alvos de interesse compreendem quatro pontos chave (todos na interface lava-sedimento). Destes, dois afloram rochas vulcânicas ácidas e básicas e dois predominantemente básicas (Figura 3). Assim, nas porções central e leste da borda da Bacia do Paraná (RS), foram selecionadas as regiões:

1) do Salto do Jacuí (SJ), onde ocorre mineralizações de ágata e derrames de composição ácida interagem com sedimentos (Michelin, 2014); 


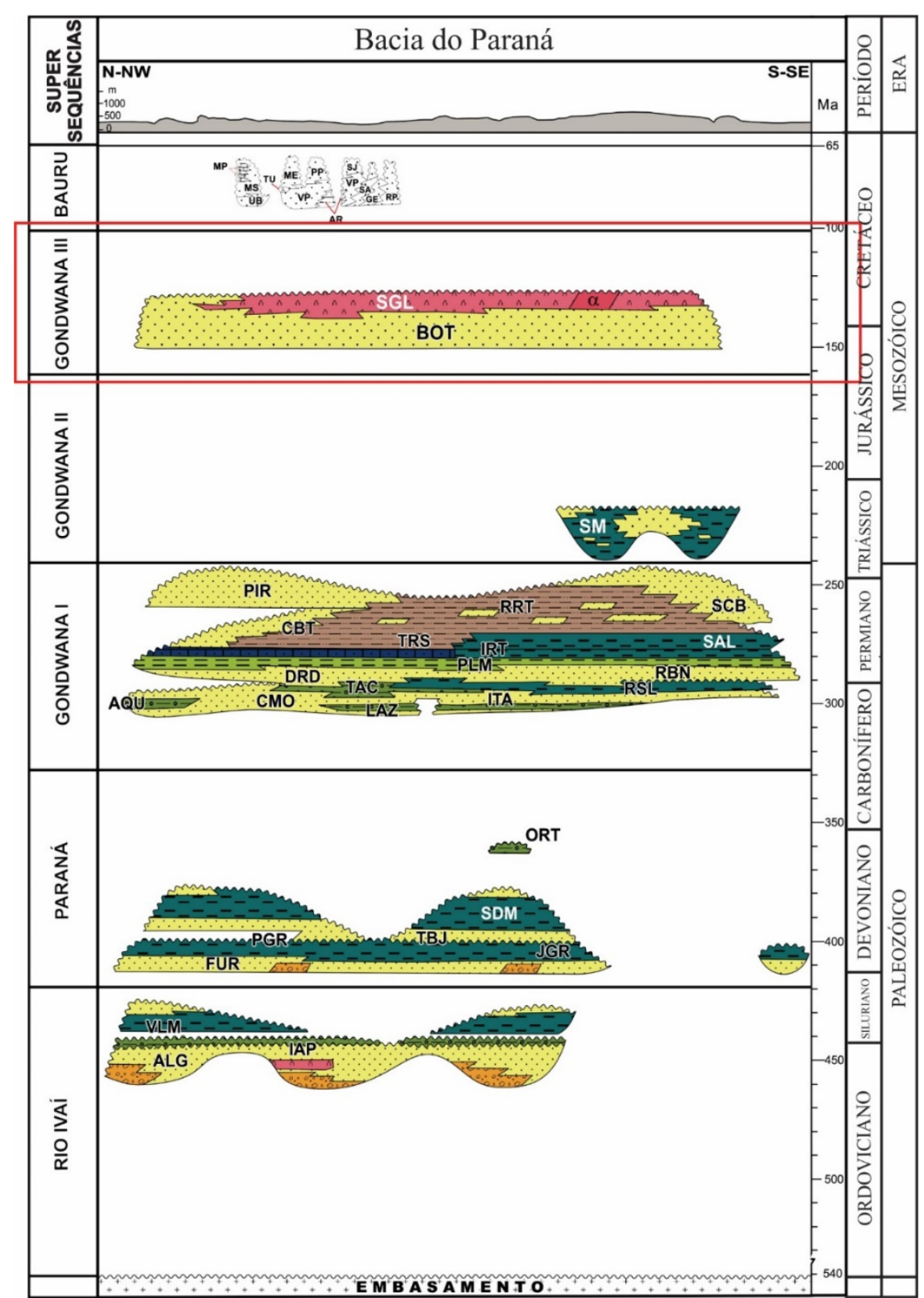

Figura 2 - Coluna estratigráfica proposta para a Bacia do Paraná destacando no quadro vermelho a Supersequência Gondwana III, caracterizada pelas Formações Botucatu (BOT) e Serra Geral (SGL), unidades de interesse deste trabalho (modificado Milani et al., 2007).

2) de Sinimbu-Herveiras (SH) e Santa Cruz do Sul (SC), ambas na porção central do estado, onde são comuns feições de interação com derrames ácidos e básicos em SH. Ao passo que em SC as feições de interação são em derrames básicos

3) de Novo Hamburgo (NH), na qual pedreiras permitem a visualização do contato entre o primeiro derrame básico e o arenito Botucatu;

4) e de Torres (TR), na região nordeste do estado, mais precisamente no Parque Estadual da Guarita com predomínio de brechas e diques de arenito em contato com derrames básicos.

\section{MATERIAIS, MÉTODOS E TÉCNICAS}

A análise de imagens aéreas, de satélite e mapas topográficos das regiões próximas as bordas atuais da Bacia do Paraná no estado do Rio Grande do Sul, permitiu a seleção das áreas de estudo em que feições de interação lavasedimento pudessem ser visualizadas, descritas e amostradas. As unidades aflorantes foram descritas detalhadamente, bem como suas relações de contato entre si, além da documentação fotográfica e coleta de amostras de rochas sedimentares, vulcânicas e porções de interação entre ambas.

Com base nas descrições foram selecionadas 71 amostras para serem 
analisadas por técnicas petrográficas e por difração de raios X (DRX).

As lâminas petrográficas foram confeccionadas de acordo com a metodologia usual sendo impregnadas com resina de cor azul para facilitar a identificação da porosidade. As lâminas petrográficas foram descritas e fotomicrografadas com um microscópio Leitz Laborluz 12 (com aumentos variando entre 2,5 e $50 \mathrm{X}$ ) utilizando-se técnicas de luz natural e de luz polarizada.

Para a análise por difração de raios X (DRX) foram utilizadas amostras da matriz das rochas vulcano-sedimentares em análises do tipo rocha total (RT) e posteriormente selecionada a fração fina $(\mathrm{FF}<4 \mu \mathrm{m})$ de algumas para detalhamento. O difratômetro usado foi um Siemens D5000 Diffraktometer do Laboratório de Difratometria de Raios X do Instituto de Geociências da Universidade Federal do Rio Grande do Sul. As condições do difratômetro foram radiação $\mathrm{KaCu}, 40 \mathrm{kV}, 30 \mathrm{~mA}$ de corrente de filamento e intervalo de 2 a $72^{\circ}(2 \theta)$.

\section{RESULTADOS}

No contato entre os arenitos da Formação Botucatu com os primeiros derrames de lavas da Formação Serra Geral evidenciam-se inúmeras feições de interação vulcanosedimentar. Os arenitos com características típicas da Formação Botucatu e outras ocorrências de arenitos, inicialmente não identificados como pertencentes a esta unidade, ocorrem como intertraps na Formação Serra Geral, seja em sua porção básica ou ácida.

Nas áreas de estudo (Figura 3) foram observadas feições de interação entre derrames de composição básica e ácida com sedimentos siliciclásticos de granulometria variando de silte a arenito grosso. De uma forma geral, as feições vulcano-sedimentares podem ser classificadas de duas formas distintas de acordo com seu processo de formação. A primeira faz referência a interação com o derrame ainda fluido, com temperatura elevada e parcialmente cristalizado, ao passo que a segunda relaciona a interação a partir de processos posteriores (erosão, intemperismo), com o derrame já consolidado.

Do ponto de vista geomorfológico as áreas de 1 a 3 (ver Figura 3) compreendem a porção denominada Planaltos e Chapadas da Bacia do Paraná. Já a área 4, situa-se no compartimento geomorfológico referente a Planícies e Tabuleiros Litorâneos, definida por uma faixa arenosa que abrange toda a porção leste do estado, caracterizada por dunas, lagunas, lagoas e falésias basálticas no litoral norte gaúcho (Ross, 2005).

As áreas analisadas caracterizam-se pela ocorrência de derrames de composição básica na base e a partir de uma altitude de aproximadamente $300 \mathrm{~m}$ (região do Salto do Jacuí) derrames de rochas ácidas começam a predominar (Nardy et al., 2008; Michelin, 2014).

Nas regiões de estudo, conforme pode ser observado na figura 3, ocorre a Formação Botucatu na base em nítido contato com a sequência vulcânica. São arenitos de granulometria variando de areia fina a grossa, coloração rosada a avermelhada, de moderada a alta maturidade textural, com grãos dominantemente arredondados de composição predominantemente quartzosa, porém, em alguns locais, observa-se um aumento na quantidade de grãos de feldspatos. Como composição mineralógica, além do quartzo e do feldspato há minerais acessórios como turmalina, apatita e zircão. Em sua maioria, as ocorrências do arenito Botucatu caracterizam-se por uma excelente porosidade, ausência de cimentação extensiva e de matriz. No entanto, em locais onde há ocorrência de rochas vulcânicas ácidas, pôde-se observar uma ausência de porosidade evidenciada pela cimentação secundária predominantemente silicosa (quartzo microcristalino, calcedônia) associada à circulação de águas ricas em sílica, lixiviadas do derrame ácido por um processo posterior (Michelin, 2014).

Intercalados aos derrames, comuns na porção mais basal da sequência vulcânica, os denominados intertraps de arenito, caracterizam-se por camadas de arenitos com dimensões métricas e algumas vezes centimétricas (Figuras 4A e 4B). São arenitos com eventual estratificação cruzada planar marcada pela alternância de lâminas com granulometria variando de grossa a média (Figura 4C), grãos subarredondados a arredondados, contatos pontuais e subordinadamente lineares. Composicionalmente são arenitos quartzosos a sub-arcóseos podendo ser cimentados por sílica microcristalina (opala e calcedônia) (Figura 4D) 


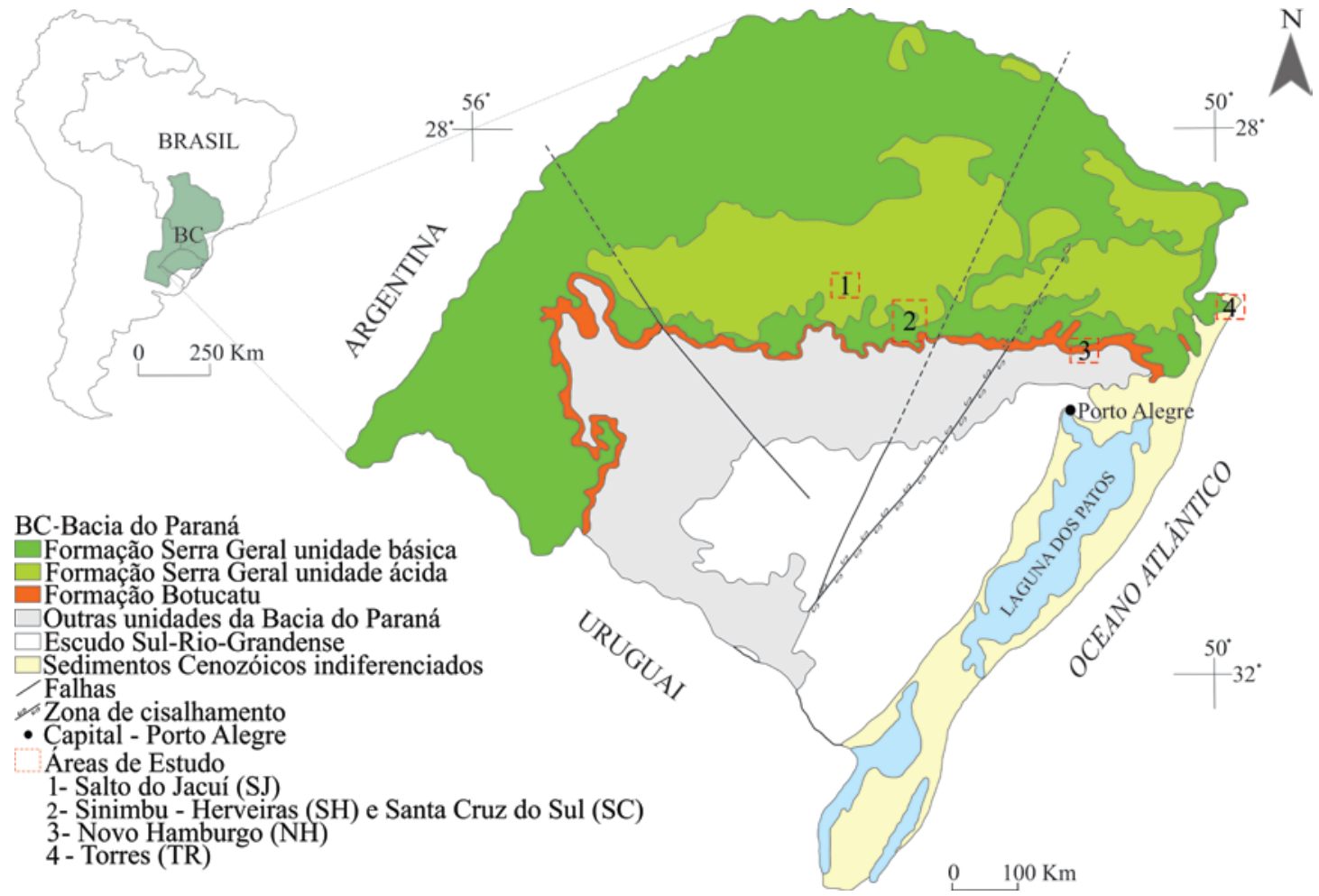

Figura 3 - Áreas de estudo na borda atual da Bacia do Paraná, estado do Rio Grande do Sul (modificado de Scherer, 2002; Janasi et al., 2011).
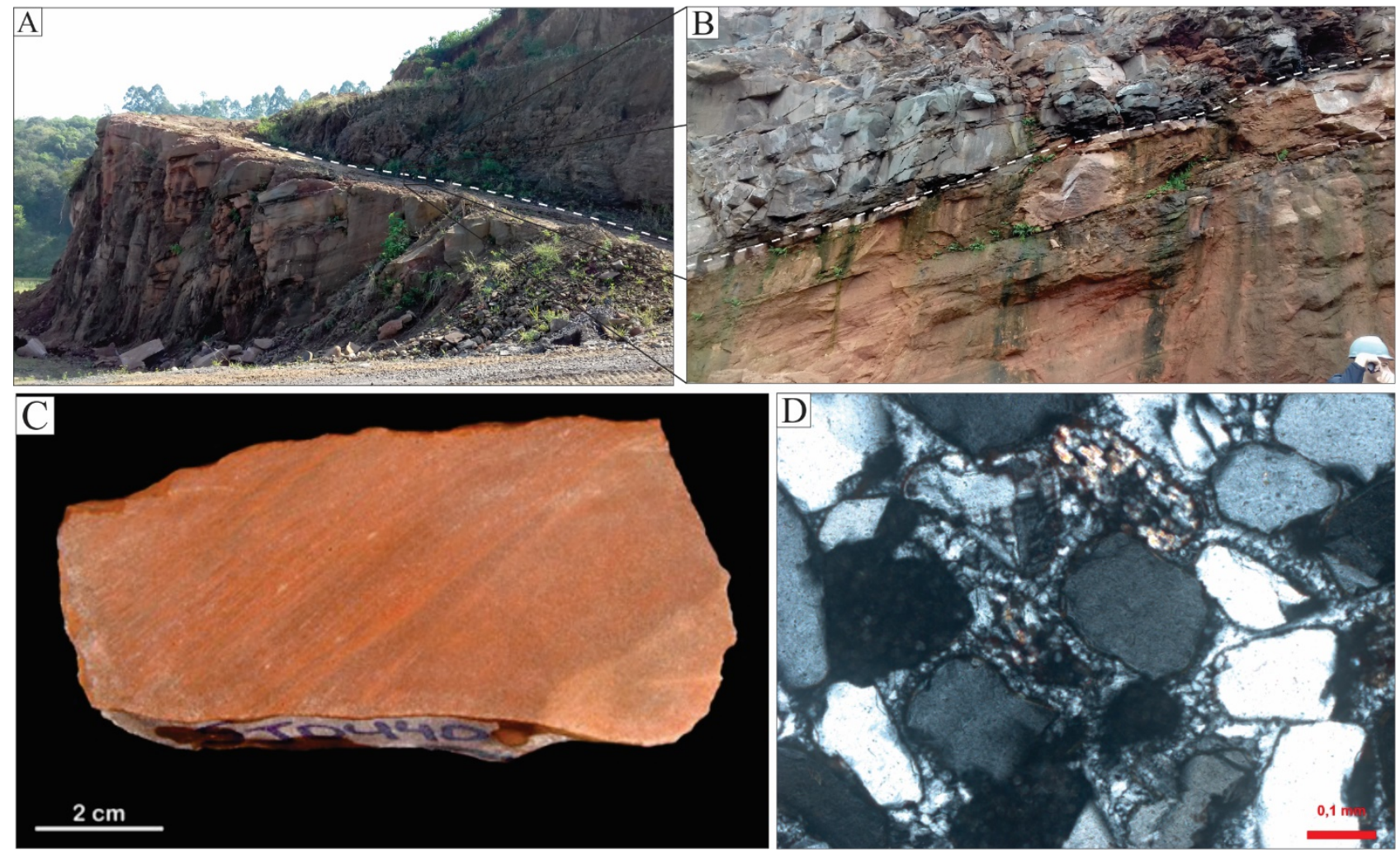

Figura 4 - Detalhes do intertrap: A) intertrap arenoso com aproximadamente $10 \mathrm{~m}$ de espessura; B) contato entre as unidades vulcano-sedimentares; C) arenito quartzo-feldspático com laminação marcada pela alternância de granulometria média a grossa e níveis de minerais pesados; D) fotomicrografia (LP) evidenciando os grãos de quartzo e feldspato subarredondados a arredondados cimentados por sílica microcristalina (calcedônia).

Estes intertraps arenosos são interpretados como indicativos de que a sedimentação eólica persistiu durante os primeiros eventos vulcânicos. Os intertraps são importantes não só por demonstrarem intervalos de quiescência entre os derrames vulcânicos (Milani et al., 
1998; Scherer, 2002), mas também por associarem-se com as feições de interação que foram descritas nas regiões de estudo.

Em termos de rochas vulcânicas, nas regiões 1 e 2 foram descritos derrames de composição básica e de composição ácida. Derrame referese um fluxo rochas fundidas (lava) que se espalha pela superfície solidificando posteriormente (Wilson, 1989).

Os derrames básicos apresentam em sua maioria disjunções horizontais e verticais, são fraturados e nas porções de base e de topo apresentam vesículas preenchidas ou parcialmente preenchidas por zeólita, calcita, quartzo microcristalino (ágata e calcedônia) e argilominerais (celadonita). Algumas cavidades maiores (geodos) também podem ser observadas de maneira subordinada, geralmente associado às fraturas. Petrograficamente, nestes litotipos, é comum a ocorrência de textura glomeroporfirítica, marcada por fenocristais euédricos a subédricos de plagioclásio e subordinadamente augita e pigeonita. Minerais opacos são relativamente comuns, tanto nos agrupamentos quanto na matriz. A matriz vítrea frequentemente apresenta feições de desvitrificação, cristais de plagioclásio ocorrem saussuritizados e sericitizados, além de cristais de piroxênio alterados. Composicionalmente estas ocorrências básicas correspondem a basaltos e basaltos andesíticos.

Em contrapartida, os derrames ácidos demonstram-se mais espessos, quando comparados aos de composição básica, possuem morfologia bastante variada (tabulares, lenticulares e lobados, entre outras) com disjunção horizontal e fraturas de forma marcante. As vesículas ocorrem de forma elíptica-alongada e são preenchidas preferencialmente por quartzo microcristalino. Em lâmina delgada, estas rochas têm textura fina e glomeropórfiros de plagioclásio, quartzo e K-feldspato, podendo ocorrer raramente alguns fenocristais de piroxênio. Pode apresentar vesículas preenchidas por sílica e argilominerais (cloritas, esmectitas). Petrograficamente, estes litotipos correspondem a dacitos.

Nos locais onde há interação com os arenitos são descritas brechas, diques de arenito, fraturas com arenitos e geodos com sedimentos, feições que vem sendo reconhecidas na interface lava- sedimento (Petry, 2006; Michelin, 2007; Petry et al., 2007; Waichel et al., 2007, 2008; Michelin, 2014).

Como brechas foram denominadas as rochas formadas pelos processos de interação constituídas de matriz arenosa e clastos de rochas vulcânicas com dimensões variadas (milimétricos a centimétricos). Ocorrem na base ou no topo dos derrames sempre em contato com o intertrap arenoso, constituindo camadas, lentes ou "bolsões”, descontínuos.

Fischer (1960), Pettijohn, (1975), McPhie et al. (1993) e Reis (2013) apresentam algumas classificações propostas para as brechas vulcânicas. Alguns autores sugerem o termo peperito para designá-las (White et al., 2000; Jerram \& Stollhofen, 2002; Skilling et al., 2002). Neste trabalho, optou-se por utilizar o termo brechas de acordo com a proposição abaixo (Figura 5).

Brechas Vulcano-sedimentares - ocorrem principalmente na porção superior dos derrames, formadas por clastos de rochas basálticas e/ou dacíticas com texturas e mineralogia variadas em matriz suportada. Clastos são angulosos a subarredondados, com dimensões variando entre a $0,5 \mathrm{~cm}$ a $10 \mathrm{~cm}$, em matriz arenosa de granulometria fina a média, grãos arredondados a subarredondados, compostos principalmente por grãos de quartzo, de feldspato e minerais secundários como a apatita (Figura 5A).

Brechas vulcânicas - clastos angulosos de basalto ou dacito em matriz suportada, semelhante à descrita nas brechas sedimentares, porém mais argilosa. Os clastos caracterizam-se por apresentarem composições e texturas semelhantes indicando associação com um único derrame. As brechas posicionam-se na base dos derrames junto ao contato com o intertrap e a partir destas pode ocorrer a formação e ramificação dos diques de arenito (Figura 5E).

Autobrechas - maciças, mal selecionadas e compostas por fragmentos de basaltos angulosos, imersos em matriz basáltica, arenosa ou carbonática (Figura 5D).

Outras feições descritas foram:

Diques de arenito - apresentam ramificações e migram por entre as porções de base dos derrames diminuindo a largura em direção ao topo (Figura 5F). O arenito de preenchimento é 


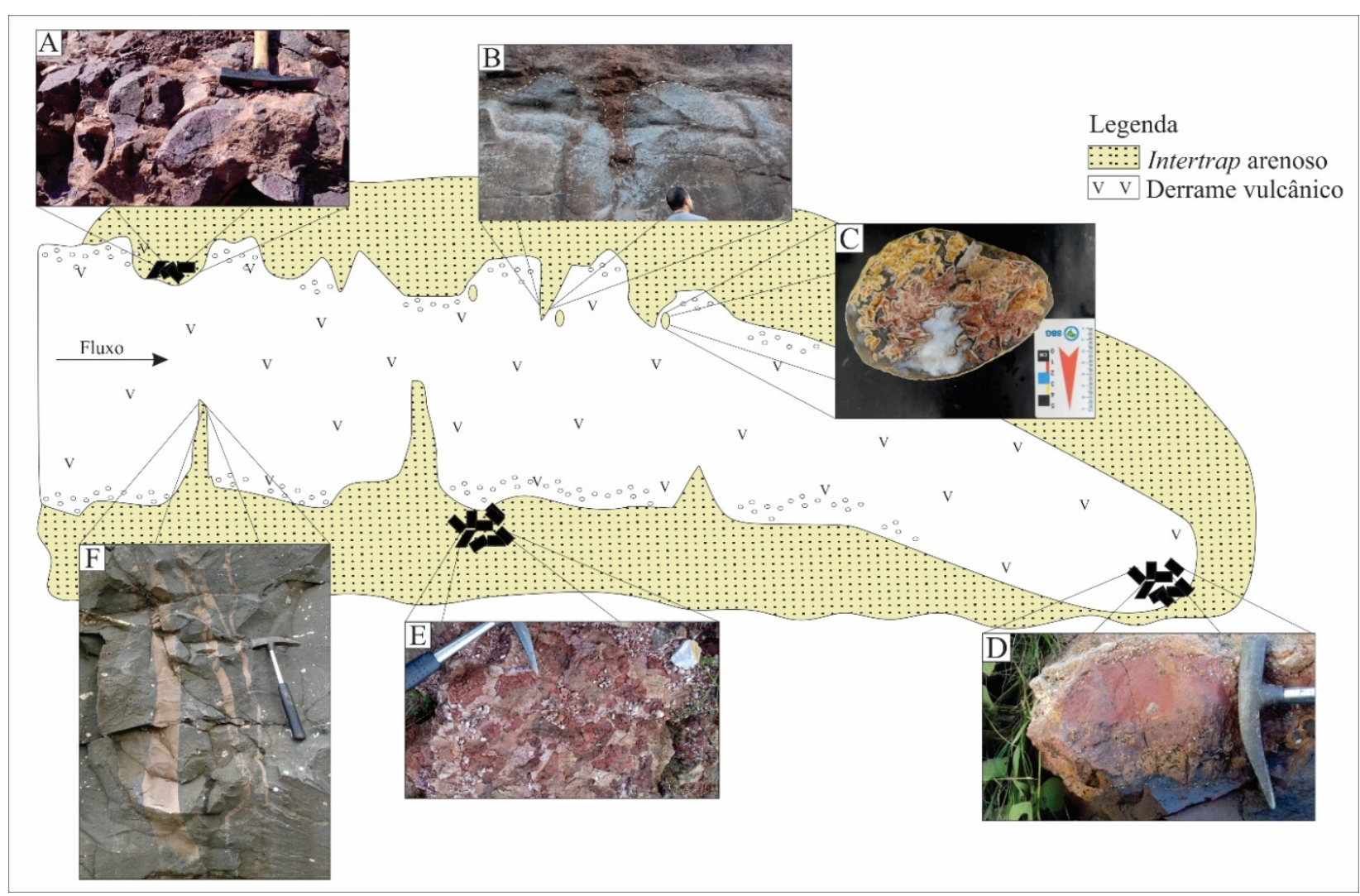

Figura 5 - Esboço esquemático representando um derrame magmático recobrindo dunas eólicas ativas e gerando feições de interação entre a lava e o sedimento: A) brecha vulcano-sedimentar; B) fraturas preenchidas por sedimentos siliciclásticos de granulometria fina a grossa; C) geodo preenchido por sedimentos sílticos, representam processos posteriores ao evento vulcânico; D) autobrecha; E) brecha vulcânica e F) diques de arenito que representam produtos gerados durante o posicionamento da lava ainda fluida sobre os sedimentos.

fino a médio, com grãos subangulosos a arredondados de quartzo, feldspato e fragmentos líticos da encaixante e/ou de rochas sotopostas (basaltos e dacitos). O contato entre os grãos é pontual e linear e como nos intertraps, a cimentação é predominantemente silicosa. Em alguns pontos ao longo do contato do dique com a rocha encaixante ocorrem bordas de reação.

Fraturas com arenitos - fraturas de resfriamento são comuns no topo dos derrames, estas podem ser preenchidas por um novo pulso na sedimentação e eventualmente podem apresentar uma estratificação incipiente. Neste caso, consideram-se tanto fraturas perpendiculares ao fluxo magmático quanto aquelas paralelas (Figura 5B).

Geodos com sedimentos - geodos são cavidades formadas durante os processos de desgaseificação das lavas sendo preenchidos posteriormente por soluções silicosas caracterizando um evento epigenético (Duarte et al., 2005). Geodos preenchidos por sedimentos foram descritos exclusivamente na região do Salto do Jacuí por Michelin (2014). Estas cavidades são preenchidas por clastos centimétricos de siltito argiloso, cimentados por calcedônia, opala e até mesmo ágata. Os clastos de siltito são de coloração avermelhada e compostos predominantemente por fragmentos micáceos orientados em matriz argilosa. Estes geodos ocorrem nas porções de meio e topo dos derrames, nas proximidades de fraturas preenchidas por sedimentos e de diques de arenito, além disso, podem, por vezes, estar associados com veios preenchidos por opala (Figura 5C).

Dunas Preservadas - as áreas 3 (Figura 6A) e 4 (Figura 6B) recebem destaque pela excelente preservação das paleodunas. Estas feições já haviam sido relatadas por Waichel et al. (2008) e registram o momento em que o primeiro derrame da Formação Serra Geral recobre dunas ainda ativas pertencentes à Formação Botucatu. Os arenitos quartzofeldspáticos que compõem estas dunas são caracterizados pela estratificação cruzada acanalada de grande porte (Figura 6C), grãos foscos arredondados a subarredondados, com alta maturidade textural e cimentação carbonática (Figura 6D). 

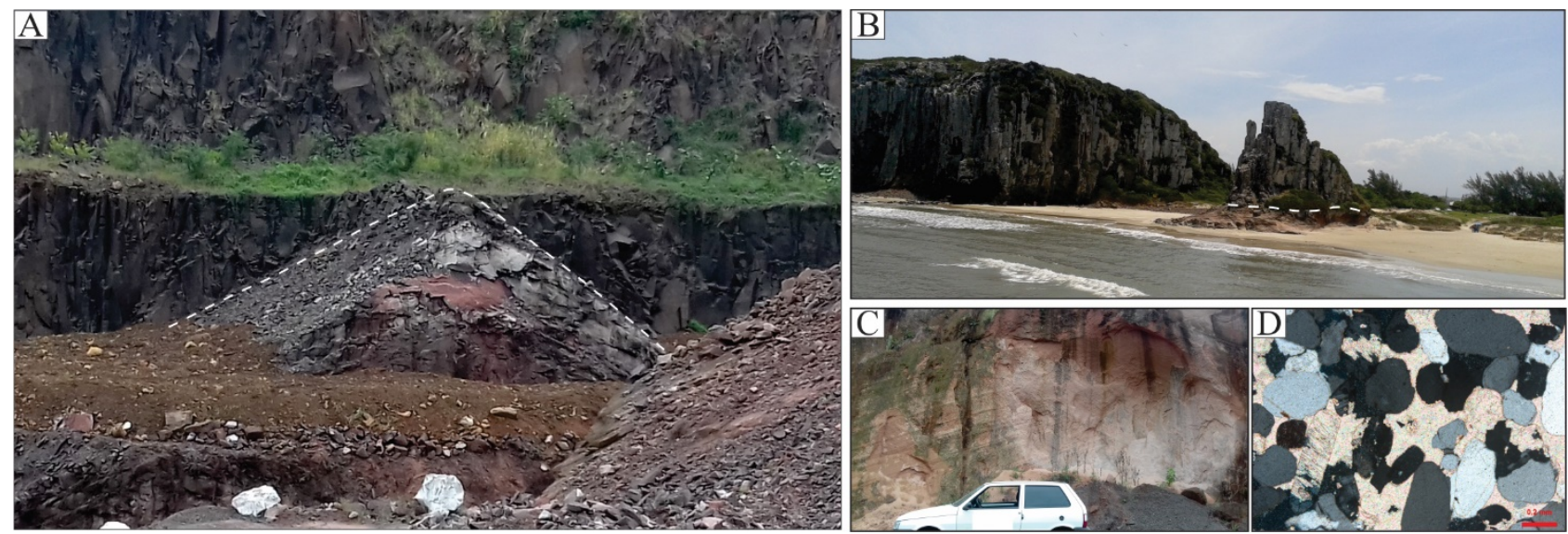

Figura 6 - Áreas recobertas do paleo-deserto Botucatu pelos primeiros episódios vulcânicos da Formação Serra Geral, os quais propiciaram a preservação de dunas: A) duna preservada na região de Novo Hamburgo (NH- área 3); B) preservação de duna observada na região do Parque Nacional das Guaritas em Torres (TR- área 4), o tracejado em branco indica o contato entre as duas unidades; C) arenito quartzo-feldspático com estratificação cruzada acanalada de grande porte; D) fotomicrografia evidenciando o arredondamento dos grãos de quartzo e feldspato e a cimentação por carbonato.

Uma vez identificadas e descritas estas feições, buscou-se uma correlação destas com seu posicionamento nas áreas estudadas. Desta maneira, percebe-se que na porção leste da borda da Bacia (áreas 3 e 4), além das dunas preservadas, diques de arenito, brechas vulcânicas e autobrechas também são reconhecidos. Em contrapartida, brechas vulcano-sedimentares e fraturas preenchidas por arenitos foram descritos nas áreas 1 e 2 (Quadro 1).

\begin{tabular}{|c|c|c|c|c|c|c|c|c|}
\hline \multicolumn{2}{|r|}{ Área } & $\begin{array}{c}\text { Dunas } \\
\text { Preservadas }\end{array}$ & $\begin{array}{c}\text { Brechas } \\
\text { vulcânicas }\end{array}$ & $\begin{array}{l}\text { Diques } \\
\text { de } \\
\text { arenitos }\end{array}$ & Autobrechas & $\begin{array}{c}\text { Brechas } \\
\text { vulcano- } \\
\text { sedimentares }\end{array}$ & $\begin{array}{c}\text { Fraturas } \\
\text { com } \\
\text { arenitos }\end{array}$ & $\begin{array}{l}\text { Geodos com } \\
\text { Sedimentos }\end{array}$ \\
\hline 1 & Salto do Jacuí & & $\mathbf{X}$ & $\mathbf{X}$ & $\mathbf{X}$ & $X$ & $\mathbf{X}$ & $\mathrm{X}$ \\
\hline \multirow{2}{*}{2} & $\begin{array}{l}\text { Sinimbú- } \\
\text { Herveiras }\end{array}$ & & $\mathbf{X}$ & $\mathbf{X}$ & & $\mathbf{X}$ & & \\
\hline & Santa Cruz & & $\mathbf{X}$ & $\mathbf{X}$ & & & & \\
\hline 3 & $\begin{array}{c}\text { Novo } \\
\text { Hamburgo }\end{array}$ & $\mathbf{X}$ & $\mathbf{X}$ & $\mathbf{X}$ & & & & \\
\hline 4 & Torres & $\mathbf{X}$ & $\mathbf{X}$ & $\mathbf{X}$ & & & & \\
\hline
\end{tabular}

Quadro 1 - Feições de interação entre rochas vulcânicas e rochas sedimentares observadas nas diferentes regiões de estudo; $\mathrm{O}$ " $\mathrm{X}$ “ indica que a feição foi observada e descrita.

\section{DISCUSSÕES}

Feições de interação entre rochas vulcânicas e sedimentares ocorrem na base e no topo dos primeiros derrames, seja de composição básica ou ácida, da Formação Serra Geral, na borda da Bacia do Paraná. O processo ocorre de diferentes formas em função da temperatura das rochas vulcânicas e do tipo de sedimento. E um estágio inicial quando a lava, com temperatura relativamente elevada e ainda em processo de cristalização, flui sobre os sedimentos há formação de brechas vulcânicas, autobrechas e diques de arenito. Trata-se de um processo dinâmico onde a presença de água ou umidade favorece a interação. Numa segunda etapa, as feições são formadas após o resfriamento, em condições superficiais de erosão e intemperismo, originando fraturas preenchidas por sedimentos, geodos com sedimentos e brechas vulcanosedimentares.

Interações concomitantes ao derrame estão diretamente associadas à presença de sedimentos saturados em água (Mizusaki, 1986; Reis, 2013; Michelin, 2014). Ao fluir sobre estes sedimentos o derrame desencadeia os processos de fluidização/vaporização instantânea, devido as suas temperaturas elevadas. A água presente nos sedimentos inconsolidados é convertida em vapor que fica confinado na base 
dos derrames em pressões elevadas. Com o arrefecimento do derrame, inúmeras fraturas de resfriamento ou diaclases surgem, ocasionando a redução da pressão e consequente expulsão do sedimento ao longo da zona de alívio de pressão, alargando e preenchendo as fraturas com o sedimento inicialmente vaporizado. $\mathrm{O}$ processo dispende energia e a base dos derrames é retrabalhada pelo fluxo de vapor, envolvendo o "arranque" e formação de clastos da rocha vulcânica. Neste caso, todos os clastos

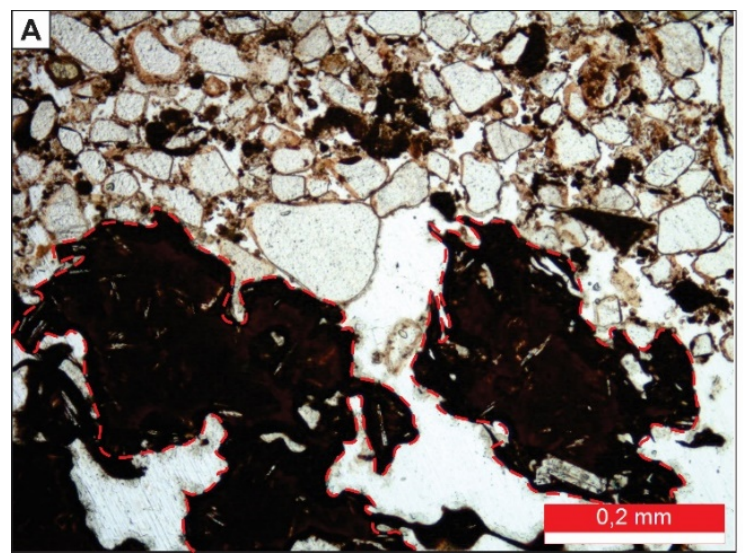

de origem vulcânica na brecha possuem textura e mineralogia semelhantes, além de bordas de reação no contato vulcânica/sedimento. Em algumas situações os clastos vulcânicos apresentam formas ameboides (Figura 7A) e fenocristais de piroxênio e plagioclásio orientados, indicativos de fluidez do material em contato com o sedimento. Dessa maneira, as bordas de reação são interpretadas como indício de lavas com temperatura ainda elevada (Figura 7B).

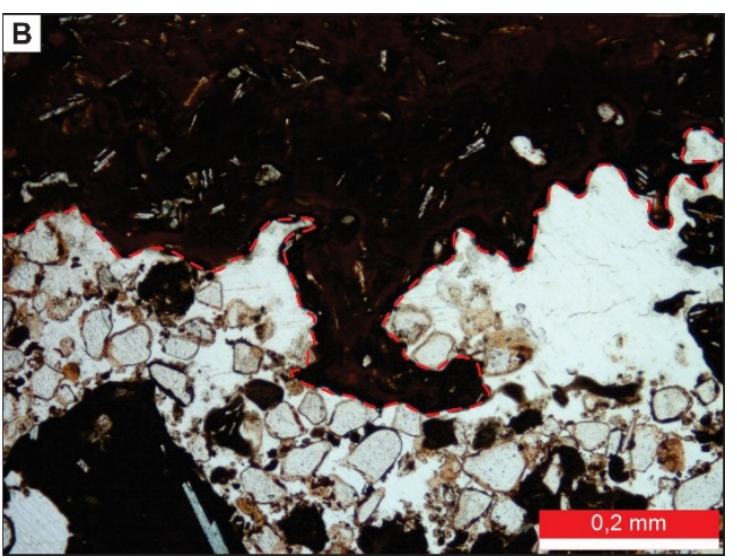

Figura 8 - Fotomicrografias (LN) do contato entre a lava fluida e o sedimento inconsolidado durante o processo de formação da brecha vulcanoclástica: A) clastos vulcânicos com formas ameboides intensamente alterados com resquícios de fenocristais de plagioclásio e piroxênio em uma matriz vítrea em processo de mesóstese; B) bordas de reação no contato do basalto com o arenito.

Podem também formar-se autobrechas, em depósitos muito localizados e representativos da frente de derrames, onde há brechação da lava parcialmente cristalizada, formação de matriz vulcânica e posteriormente cimentação por carbonatos. Autobrechas ocorrem de forma concomitante ao evento magmático por meio de processos atuantes durante o movimento da lava, parcialmente solidificada, em presença de um declive na topografia, o qual proporciona o englobamento dos clastos (Reis, 2013; Michelin, 2014).

Para as feições posteriores ao magmatismo, reconhece-se que estas são formadas por processos intempéricos atuantes nas rochas vulcânicas. As fraturas preenchidas por sedimentos são geradas quando fraturas ou diaclases do derrame basáltico são posteriormente preenchidas pelo sedimento ainda inconsolidado, provavelmente fruto de uma recorrência da sedimentação eólica, a mesma que ocasionalmente poderia dar origem aos intertraps arenosos. Como preenchimento destas fraturas, é comum ainda a ocorrência de fragmentos de vulcânicas ácidas/básicas, com pouco ou nenhum retrabalhamento, mas com elevado grau de alteração.

Sedimentos de granulometria argila e silte foram reconhecidos como preenchimento de geodos. O processo genético destes geodos pode estar relacionado com a abertura singenética de cavidades como produto da desgaseificação do magma, e preenchidas posteriormente por sedimento (silte-argila) decantado a partir de águas de infiltração que percolaram por fraturas, microfraturas e vesículas. O processo de preenchimento dos geodos permite que os sedimentos sejam laminados. Como são sedimentos finos e com abundantes partículas de micas orientadas, estes são provenientes da sedimentação característica em interdunas (Waichel, 2006; Michelin, 2014).

\section{CONCLUSÕES}

Foram identificadas feições vulcanosedimentares, resultantes da interação entre os arenitos eólicos da Formação Botucatu com os derrames de composição básica e também ácida, na borda atual da Bacia do Paraná, no estado do Rio Grande do Sul, em cinco regiões de estudo 
previamente selecionadas. As feições vulcanosedimentares são descritas como brechas (vulcânicas, vulcano-sedimentares e autobrechas), diques de arenito, fraturas com arenitos e geodos com sedimentos, além de estrias de fluxo. A gênese dessas feições resulta de processos ligados a temperatura das lavas e composição e presença de águas nos sedimentos. A formação de brechas vulcânicas e diques de arenito reflete um processo dinâmico onde a temperatura elevada das lavas, em processo de cristalização, em contraste com a água ou umidade presente nos sedimentos favorecem a interação entre ambos através da fluidização/ vaporização. Este processo promove a retirada de fragmentos da base do derrame, formando assim os clastos de lava. As bordas de reação na interface lava/sedimento e a presença de clastos com aspecto ameboides e fenocristais orientados, são indicativos de que a gênese dessas feições vulcano-sedimentares ocorreu em temperaturas elevadas. As autobrechas formam-se durante o evento magmático e originam-se na porção frontal dos derrames através da brechação e englobamento da lava parcialmente solidificada, sempre em presença de um declive topográfico. Já as fraturas preenchidas por sedimentos, geodos com sedimentos e brechas vulcanosedimentares são originados após o resfriamento do derrame em condições superficiais de intemperismo e erosão. A presença de intertraps arenosos entre os derrames são indicativos de uma recorrência da atividade eólica durante o magmatismo, e está associada com a formação de fraturas preenchidas por sedimentos e brechas vulcanosedimentares. Nos geodos com sedi-mentos, o preenchimento destes com sedimentos na fração silte-argila e fragmentos de micas orientadas tem sido atribuído a infiltração de águas superficiais provavelmente em situação de interdunas.

\section{AGRADECIMENTOS}

Este artigo faz parte da dissertação de mestrado do primeiro autor, que agradece a CAPES pela concessão bolsa de pesquisa e pelo suporte financeiro do presente trabalho. Os autores agradecem aos colegas Isaque Rodrigues, Nelson Lisboa e Camile Urban pelas sugestões e comentários que ajudaram a aperfeiçoar este trabalho.

\section{REFERÊNCIAS}

ALLEN, R.L. Reconstruction of the tectonic, volcanic and sedimentary setting of strongly deformed $\mathrm{Zn}-\mathrm{Cu}$ massive sufide deposits at Benambra. Victoria, Australia, Economic Geology, v. 87, p. 825-854, 1992

ALMEIDA, F.F.M. Botucatu, um deserto triássico da América do Sul. Notas Preliminares e Estudos da Divisão de Geologia e Mineralogia do DNPM, v. 86, p. 1-21, 1954.

ARIOLI, E.E.; LICHT, O.A.B.; VASCONCELLOS, E.M.G.; BONNET, K.L.; SANTOS, E.M. Faciologia vulcânica da Formação Serra Geral na região de Guarapuava, Paraná. In: IV SIMPÓSIO DE VULCANISMO E AMBIENTES ASSOCIADOS, 4, 2008. Foz do Iguaçu. Anais... Foz do Iguaçu, SBG. 2008. 1CD-ROM.

BOULTER, C.A. High-level peperitic sills at Rio Tinto, Spain: implications for stratigraphy and mineralization. Transactions of the Institution of Mining and Metallurgy, v. 102, p. 30-38, 1993

BRANNEY, M. \& SUTHREN, R. High-level peperitic sills in the English Lake District: distinction from block lavas, and implications for Borrowdale Volcanic Group stratigraphy. Geology Journal, v. 23, p. 171-187, 1988.

BRANNEY, M.; SUTHREN, R. High-level peperiticsills in the English Lake District: distinction from block lavas, and implications for Borrowdale Volcanic Group stratigraphy. Geology Journal, v. 23, p. 171-187, 1988.

BUSBY-SPERA, C. \& WHITE, J.L. Variation in peperite textures associated with differing host-sediment properties. Bulletin of Volcanology, v. 49, p. 765-776, 1987.

DUARTE, L.C.; HARTMANN, L.A.; VASCONCELLOS, M.A.Z. Epigenetic geode formation in the world class amethyst deposits of the southern Paraná Basaltic Province. In: SIMPÓSIO
BRASILEIRO DE METALOGENIA, 1, Gramado. 2005. Anais... Gramado: Sociedade Brasileira de Geologia, 5p., CDROM.

FISCHER, R.V. Classification of volcanic breccias. Geologic Society American Bulletin, v. 71, p. 973-982, 1960.

HARTMANN, L.A.; DUARTE, L.C.; MASSONNE, H.-J.; MICHELIN, C.; ROSENSTENGEL, L.M.; BERGMANN, M.; THEYE, T.; PERTILLE, J.; ARENA, K.R.; DUARTE, S.K.; PINTO, V.M.; BARBOZA, E.G.; ROSA, M.L.C.C.; WILDNER, W. Sequential opening and filling of cavities forming vesicles, amygdales and giant amethyst geodes in lavas from the southern Paraná volcanic province, Brazil and Uruguay. International Geology Review, v. 54, p. 1-14, 2012a.

HARTMANN, L.A.; ARENA, K.R.; DUARTE, S.K. Geological relationships of basalts, andesites and sand injectites at the base of the Paraná volcanic province, Torres, Brazil. Journal of Volcanology and Geothermal Research, v. 237-238, p. 97-111, 2012b

HEEMANN, R. Geologia, controles e guias prospectivos para depósitos de ágata na região do Salto do Jacuí. Porto Alegre, 1997, 107p. Dissertação (Mestrado em Engenharia), Universidade Federal do Rio Grande do Sul.

HOLE, M.; JOLLEY, D.; HARTLEY, A.; LELEU, S.; JOHN, N.; BALL, M. Lava-sediment interactions in an Old Red Sandstone basin, NE Scotland. Journal of the Geological Society, v. 170, p. 641-655, 2013.

HOLZ, M.; SOARES, A.P.; SOARES P.C. Preservation of aeolian dunes by pahoehoe lava: An example from the Botucatu Formation (Early Cretaceous) in Mato Grosso do Sul state (Brazil), western margin of the Paraná Basin in South America. Journal of South American Earth 
Sciences, v. 25, p. 398-404, 2008.

JANASI, V.D.A.; de FREITAS, V.A.; HEAMAN, L.H. The onset of flood basalt volcanism, Northern Paraná Basin, Brazil: a precise U-Pb baddeleyite/zircon age for a Chapecótype dacite. Earth and Planetary Science Letters, v. 302, n. 1, p. 147-153, 2011.

JERRAM, D.A.; MOUNTNEY, N.; HOLZFÖRSTER, F.; STOLLHOFEN, H. Internal stratigraphic relationships in the Etendeka Group in the Huab Basin, NW Namibia. Journal of Geodynamics, v. 28, p. 393-418, 1999a.

JERRAM, D.A.; MOUNTNEY, F.; STOLLHOFEN, H. Facies architecture of the Etjo Sandstone Formation and its interaction with the basal Etendeka Flood Basalts of northwest Namibia: implications for offshore prospectivity. In: CAMERON, N.R., BATE, R.H., CLURE, V.S. (Eds.), The Oil and Gas Habitats of the South Atlantic. Geological Society London, Special Publications, v. 153, p. 367-380, 1999b.

JERRAM, D.; MOUNTNEY, N.; HOWELL, J.A.; LONG, D.; STOLLHOFEN, H. Death of a sand sea: an active aeolian erg systematically buried by the Etendeka flood basalts of NW Namibia. Journal of the Geological Society, v. 157, p. 513516, 2000.

JERRAM, D. \& STOLLHOFEN, H. Lava-sediment interaction in the desert settings; are all peperite-like textures the result of magma-water interaction?. Journal of Volcanology and Geothermal Research, v. 114, p. 231-249, 2002.

LORENZ, B.E. Mud-magma interactions in the Dunnage Melange, Newfoundland. In: KOKELAAR, B.P., HOWELLS, M. (Eds.), Volcanic and Associated Sedimentary and Tectonic Processes in Modern and Ancient Marginal Basins. Geological Society London, Special Publication, p. 271-277, 1984.

LUCHETTI, A.C.F.; NARDY, A.J.R.; MACHADO, F. B.; MADEIRA, J.E.O.; ARNOSIO, J.M. Peperites and sedimentary deposits within the silicic volcanic sequences of the PMP. Solid Earth, v. 5, p. 121-130, 2014.

MACDONALD, G.A. An intrusive peperite at San Pedro Hill, California. Calif. Univ. Publ. Dept. Geology Sciences Bulletin, v. 24, p. 329-338, 1939.

MACHADO, F.B.; NARDY, A.J.R.; ROCHA JR., E.R.V.; MARQUES, L.S.; OLIVEIRA, M.A.F. Geologia e litogeoquímica da Formação Serra Geral nos estados de Mato Grosso e Mato Grosso do Sul. Geociências, Universidade Estadual Paulista, v. 28, p. 523-540, 2009.

MCPHIE, J. The Tennant Creek Porphyry revisited: a synsedimentary sill with peperite margins, Early Proterozoic, Northern Territory. Australian Journal of Earth Sciences, v. 40, p. 545-558, 1993.

MCPHIE, J.; DOYLE, M.; ALLEN, R. Volcanic Textures. A guide to the interpretation of textures in volcanic rocks. Hobart, University of Tasmania, 198p. 1993.

MCPHIE, J. \& HUNNS, S.R. Secondary welding of submarine, pumice-lithic breccia at Mount Chalmers, Queensland, Australia. Bulletin Volcanology, v. 57, p. 170-178, 1995.

MCPHIE, J. \& ORTH, K. Peperite, pumice and perlite in submarine volcanic successions: implications for VHMS mineralisation. Proceedings of Pacrim '99, Bali, Indonesia, p. 643-648, 1999.

MELFI, A.J.; PICCIRILLO, E.M.; NARDY, A.J.R. Geological and magmatic aspects of the Paraná Basin: an introduction. In: PICCIRILLO, E.M. \& MELFI, A.J. (Eds.). The Mesozoic flood volcanism of the Paraná Basin: petrogenetic and geophisycal aspects. Instituto Astronômico e Geofísico, Universidade de São Paulo, p 1-13, 1988.

MICHELIN, C.R.L. Seqüência de formação das cavidades no basalto e seu preenchimento com zeólitas, arenito, ágata e ametista, Derrame Miolo, São Martinho da Serra, Rio Grande do Sul, Brasil. Porto Alegre, 2007, 50p. Dissertação (Mestrado em Geociências), Instituto de Geociências,
Universidade Federal do Rio Grande do Sul.

MICHELIN, C.R.L. Ágata do Distrito Mineiro de Salto do Jacuí (Rio Grande do Sul, Brasil) - uma caracterização com base em técnicas estratigráficas, petrográficas, geoquímicas e isotópicas. Porto Alegre, 2014. 162p. Tese (Doutorado em Geociências), Instituto de Geociências, Universidade Federal do Rio Grande do Sul.

MILANI, E.J. Evolução tectono-estratigráfica da Bacia do Paraná e seu relacionamento com a geodinâmica fanerozóica do Gondwana sul-ocidental. Porto Alegre, 1997. 225p. Tese (Doutorado em Geociências), Instituto de Geociências, Curso de Pós-Graduação em Geociências, Universidade Federal do Rio Grande do Sul.

MILANI, E.J.; FACCINI, U.F.; SCHERER, C.M.S.; ARAÚJO, L.M.; CUPERTINO, J.A. Sequences and stratigraphic hierarchy of the Paraná Basin (Ordovincian to Cretaceous), Southern Brazil. In: AMOS, A.J.; LÓPEZ-GAMUDI, O.; ROCHA-CAMPOS, A.C. (Eds.). Sedimentary basins of South America, Amsterdam, Elsevier, p. 449, 1998.

MILANI, E.J.; MELO, J.H.G.; SOUZA, P.A.; FERNANDES, L.A.; FRANÇA, A.B. Bacia do Paraná. Boletim de Geociências da Petrobras, v. 15, n. 2, p. 265-287, 2007.

MIZUSAKI, A.M.P. A utilização do microscópio eletrônico de varredura no estudo de rochas reservatório de hidrocarbonetos. In: SEMINÁRIO DE GEOLOGIA, Rio de Janeiro, 1986. Petrobrás/Depex, v. 1, p. 322-331.

MOUNTNEY, N.; HOWELL, J.; FLINTH, S., JERRAM, D.A. Aeolian and alluvial deposition within the Mesozoic Etjo Sandstone Formation, northwest Namibia. Journal of African Earth Science, v. 27, p. 175-192, 1998.

MOUNTNEY, N.; HOWELL, J.; FLINTH, S.; JERRAM, D.A. Relating eolian bounding-surface geometries to the bed forms that generated them: Etjo Formation, Cretaceous, Namibia. Geology, v. 27, p. 159-162, 1999.

MOUNTNEY, N. \& HOWELL, J. Aeolian architecture, bedform climbing and preservation space in the Cretaceous Etjo Formation, NW Namibia. Sedimentology, v. 47, p. 825-849, 2000.

NARDY, A.J.R.; MACHADO, F.B.; OLIVEIRA, M.A.F. As rochas vulcânicas mesozóicas ácidas da Bacia do Paraná: litoestratigrafia e considerações geoquímico estratigráficas. Revista Brasileira de Geociências, v. 38, n. 1, p. 178-195, 2008. PERINOTTO, J.A.J.; ETCHEBEHERE, M.L.C.; SIMÕES, L.S.A.; ZANARDO, A. Diques clásticos na Formação Corumbataí no nordeste da Bacia do Paraná, SP: Análise sistemática e significações estratigráficas, sedimentológicas e tectônicas. Geociências, v. 27, p. 469-491, 2008.

PETRI \& FÚLFARO, V. J. Geologia do Brasil. São Paulo, EDUSP, 631 p. 1983.

PETRY, K. Feições de interação vulcano-sedimentares: seu uso como indicadores de contemporaneidade no magmatismo Rodeio Velho (meso-ordoviciano) e no vulcanismo Serra Geral (cretáceo inferior). São Leopoldo RS, 2006. 88p. Dissertação (Mestrado em Geociências), Universidade do Vale do Rio do Sinos.

PETRY, K.; JERRAM, D.A.; ALMEIDA, D.P.M.; ZERFASS, H. Volcanic-sedimentary features in the Serra Geral Fm., Paraná Basin, southern Brazil: Examples of dynamic lavasediment interactions in an arid setting. Journal of Volcanology and Geothermal Research, v. 159, p. 313-325, 2007.

PETTIJOHN, F.J. Sedimentary rocks. New York, Harper \& Row, 628p., 1975.

PICCIRILLO, E.M. \& MELFI, A.J. The Mesozoic flood volcanism from the Paraná Basin (Brazil): petrogenetic and geophysical aspects. Instituto Astronômico e Geofísico, Universidade de São Paulo, 600p., 1988.

POLO, L.A. O vulcanismo ácido da Província Magmática Paraná Etendeka, na região de Gramado Xavier, RS: estratigrafia, estruturas, petrogênese e modelo eruptivo. 
São Paulo, 2014. 340p. Tese (Doutorado em Geociências) Instituto de Geociências, Universidade de São Paulo.

REIS, G.S. A Formação Serra Geral (Cretáceo, Bacia do Paraná) como análogo para os reservatórios ígneo-básicos da margem continental brasileira. Porto Alegre, 2013. 100p. Dissertação (Mestrado em Geociências), Instituto de Geociências, Universidade Federal do Rio Grande do Sul.

ROSA, C.J.P.; MCPHIE, J.; RELVAS, J.M.R.S. Distinguishing peperite from other sediment-matrix igneous breccias: Lessons from the Iberian Pyrite Belt. Journal of Volcanology and Geothermal Research, v. 315, p. 28-39, 2016.

ROSS, J.L.S. Geografia do Brasil. Edusp, 549p. 2005.

SCHERER, C.M.S. Análise estratigráfica e litofaciológica da Formação Botucatu (Cretáceo Inferior da Bacia do Paraná) no Rio Grande do Sul. Porto Alegre, 1998. 202p. Tese (Doutorado em Geociências), Instituto de Geociências, Universidade Federal do Rio Grande do Sul.

SCHERER, C.M.S. Eolian dunes of the Botucatu Formation (Cretaceous) in Southernmost Brazil: morphology and origin. Sedimentary Geology, v. 137, p. 63-84, 2000.

SCHERER, C.M.S. Preservation of aeolian genetic units by lava flows in the Lower Cretaceous of the Paraná Basin, southern Brazil. Sedimentology, v. 49, p. 97-116, 2002.

SKILLING, I.P.; WHITE, J.D.L.; MCPHIE, J. Peperite: a review of magma-sediment mingling. In: SKILLING, I.P., WHITE, J.D.L., MCPHIE, J. (Eds.), Peperite: Processes and products of Magma-Sediment Mingling. Journal of Volcanology and Geothermal Research, v. 114, p. 1-17, 2002.

SQUIRE, R.J. \& MCPHIE, J. Characteristics and origin of peperite involving coarse-grained host sediment. Journal of Volcanology and Geothermal Research, v. 114, p. 45-61, 2002.

STRIEDER, A.J. \& HEEMANN, R. Structural constraints on Paraná basalt volcanism and their implications on agate geode mineralization (Salto do Jacuí, RS, Brazil). Pesquisas em Geociências, v. 33, p. 37-50, 2006.
WAICHEL, B.L.; LIMA, E.F.; LUBACHESKY, R.; SOMMER, C.A. Pahoehoe flows from the central Paraná Continental Flood Basalts. Bulletin of Volcanology, v. 68(7/8), p. 599-610, 2006

WAICHEL, B.L.; LIMA, E.F.; SOMMER, C.A.; LUBACHESKY, R. Peperite formed by lava flows over sediments: An example from the central Paraná Continental Flood Basalts, Brazil: Journal of Volcanology and Geothermal Research, v. 159, p. 343-354, 2007.

WAICHEL, B.L.; SCHERER, C.M.S.; FRANK, H.T. Basaltic lavas covering active Aeolian dunes in the Paraná Basin in Southern Brazil: features and emplacement aspects. Journal of Volcanology and Geothermal Research, v. 169, p. 5972, 2008.

WHITE, J.D.L.; MCPHIE, J.; SKILLING, I.P. Peperite: a useful geneticterm. Bulletin Volcanology, V. 62, p. 65-66, 2000.

WILSON, M. Igneous Petrogenesis. A Global Tectonic Approach. Unwin Hyman, London, 466p. 1989.

ZALAN, P.V.; WOLFF, S.; CONCEIÇÃO, J.C.J.; ASTOLFI, M.A.M.; VIEIRA, I.S.; APPI, V.T.; ZANOTTO, O.A.; MARUES, Q. Tectonics and sedimentation of the Paraná basin. In: SIMPÓSIO DO GONDWANA, São Paulo, 1988. Anais... São Paulo [s. n.].

ZALÁN, P.V.; WOLFF, S.; ASTOLFI, M.A.M.; VIEIRA, I.S.; CONCEIÇÃO, J.C.J.; APPI, V.T.; SANTOS NETO, E.V.; CERQUEIRA, J.R.; MARQUES, A. The Paraná Basin, Brazil. In: LEIGHTON, M.W.; KOLATA, D.R.; OLTZ, D.F.; EIDEL, J.J. (Ed.). Interior cratonic basins. Tulsa. American Association of Petroleum Geologists, (AAPG. Memoir), v. 51, p. 681-708, 1990.

ZIMANOWSKI, B. \& BÜTTNER, R. Dynamic mingling of magma and liquefied sediments. Journal of Volcanology and Geothermal Research, v. 114, p. 37-44, 2002.

Submetido em 16 de outubro de 2016 Aceito em $1^{\circ}$ de março de 2017 